\title{
Selection for Low-cadmium Cultivars and Cadmium Subcellular Distribution Comparison between Two Selected Cultivars of Eggplant (Solanum Melongena L.)
}

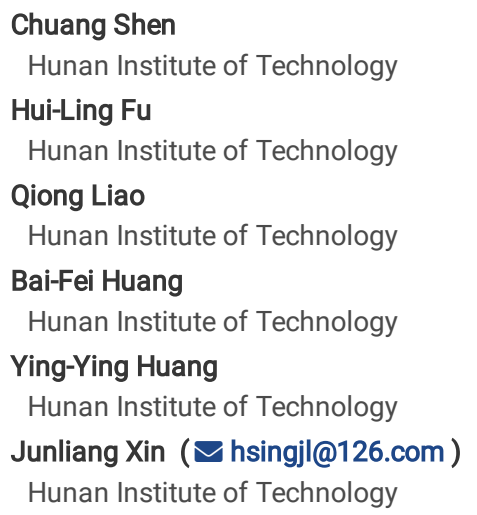

Research Article

Keywords: Eggplant, low-Cd cultivars, BRS, Cd accumulation, Subcellular distribution

Posted Date: April 12th, 2021

DOI: https://doi.org/10.21203/rs.3.rs-370182/v1

License: (c) (1) This work is licensed under a Creative Commons Attribution 4.0 International License. Read Full License 


\begin{abstract}
Excessive accumulation of cadmium (Cd) in vegetables poses a serious threat to human health; therefore, it is urgent to screen and cultivate vegetable cultivars with low $\mathrm{Cd}$ accumulation in the edible parts. Eggplant has a high tendency for $\mathrm{Cd}$ accumulation, but research on its low $\mathrm{Cd}$ accumulation cultivars is still rare. In this study, to screen low-Cd cultivars, 30 eggplant cultivars were screened using soils containing $0.22 \mathrm{mg} / \mathrm{kg}, 2.9 \mathrm{mg} / \mathrm{kg}$ (low-Cd), and $4.7 \mathrm{mg} / \mathrm{kg}$ of Cd (high-Cd). MYCQ and ZGQ were confirmed as low-Cd cultivars, BXGZ and WCCQ were confirmed as high-Cd cultivars, and a 2.52-3.88 fold difference in $\mathrm{Cd}$ concentration was observed in their fruits. The subcellular distribution revealed that the root cell wall and vacuole Cd concentrations of a typical low-Cd cultivar (MYCQ) were significantly higher than those of a typical high-Cd cultivar (BXGZ); however, the Cd concentrations in the cell wall and vacuole in fruits, leaves, and stems were significantly lower in MYCQ than in BXGZ. These results indicated that the low-Cd cultivars of eggplant could lessen Cd toxicity through the elevated $\mathrm{Cd}$ retention and sequestration levels of root cell walls and vacuoles, thus reducing Cd transport from roots to aboveground tissues, leading to low $\mathrm{Cd}$ accumulation. The findings of this study can provide a physiological and biochemical foundation for the screening and breeding of low-Cd cultivars of fruit vegetables and demonstrates that the application of low-Cd cultivars is necessary for food safety in humans.
\end{abstract}

\title{
Introduction
}

Cadmium (Cd) is highly toxic to plants and can pass through the food chain causing harm to human health (Grant et al. 2008). During the past decades, industrial and agricultural development has triggered severe soil heavy metal pollution around the world. According to the results of the National Multipurpose Regional Geochemical Survey of China in 2014, the pollutant content in $19.4 \%$ of the investigated arable land was above the environmental quality standard for soils, among which Cd pollution was one of the most serious (Li et al. 2014). Studies have revealed that $70-90 \%$ of the Cd in the human body originates from vegetables (Shen et al. 2017). Therefore, effective methods to minimize $\mathrm{Cd}$ assimilation in the human body are necessary and urgent for human health.

Cadmium accumulation in plant shoots depends on Cd entry through the roots, sequestration within root vacuoles, translocation in the xylem and phloem, and Cd dilution within the plant shoot throughout its growth (Greger and Löfstedt 2004). Pollution-safe cultivar (PSC) strategy has been proven to be a highly efficient way to reduce Cd toxicity risk by screening and breeding low-Cd cultivars (Huang et al. 2018). Due to Cd uptake and accumulation differing greatly not only among plant species but also among cultivars, the implementation of Cd-PSC strategy can be guaranteed. To date, the Cd-PSC strategy has been utilized in water spinach (Ipomoea aquatica Forsk.) (Wang et al. 2009), Chinese flowering cabbage (Brassica campestris L) (Qiu et al. 2011), hot pepper (Capsicum annuum L.) (Xin, Huang, Liu, et al. 2013), leafy lettuce (Lactuca sativa L.) (Zhang et al. 2013), pakchoi (Brassica chinensis L.) (Zhou et al. 2016), and Chinese kale (Brassica alboglabra L.) (Guo et al. 2018); the Cd concentrations of edible parts in these low-Cd cultivars are $60-80 \%$, lower than those of the high-Cd cultivars on average.

Eggplant (Solanum melongena L.) is a vegetable of great economic and nutritional value that has been widely cultivated worldwide, especially in China (Saini and Kaushik 2019). According to a survey by the Agriculture Organization of the United Nations (FAO) in 2019, China produced approximately 36 million tons of eggplant, of which more than $90 \%$ were consumed in the domestic market (FAOSTAT 2020). However, the investigation suggested that eggplants had a high $\mathrm{Cd}$ accumulation potential, and the $\mathrm{Cd}$ concentration in its fruit could exceed the national food safety standard by 10 times when grown in moderately polluted farmland (Li et al. 2013; Yuan et al. 2019). Based on the annual production and consumption of eggplant and its Cd pollution status in China, it is extremely important to implement the Cd-PSC strategy to obtain eggplant cultivars with low Cd accumulation in fruits (low-Cd cultivars). To date, the relevant research on Cd-PSC for eggplants is rather limited.

In this study, 30 different cultivars of commercially available eggplant were investigated to screen low-Cd cultivars. The low-Cd accumulation mechanisms of eggplant were explained by comparing $\mathrm{Cd}$ tolerance, transportation, and subcellular distribution with cultivars of high-Cd accumulation in fruits (high-Cd cultivars). We hypothesized that (i) the Cd concentrations of Cd-PSC and high-Cd eggplant cultivars could be attributed to their different root Cd uptake and $\mathrm{Cd}$ translocation capacities; and that (ii) the $\mathrm{Cd}$ subcellular distribution analysis of low-Cd and high-Cd eggplant cultivars would help us determine the crucial factors that contribute to the differences in Cd accumulation capacity.

\section{Materials And Methods Experimental site and soil}

The pot experiment was performed in a greenhouse at the Hunan Institute of Technology $\left(112^{\circ} 41 \mathrm{E}, 26^{\circ} 52 \mathrm{~N}\right)$, Hunan Province, China. Experimental clean soil was collected from a nearby farmland with a Cd concentration of $0.22 \mathrm{mg} / \mathrm{kg}$, so it could be used as a control (CK). The soil pH, organic matter content, total $\mathrm{N}$, available $\mathrm{P}$, available $\mathrm{K}$, and total Cd concentration were $6.52,1.72,1.5 \mathrm{~g} / \mathrm{kg}, 95.4,128.3$, and $0.25 \mathrm{mg} / \mathrm{kg}$, respectively. Low-Cd and high-Cd soils were prepared by mixing clean soil with appropriate amounts of $\mathrm{Cd}\left(\mathrm{NO}_{3}\right)_{2}$ solution. After a period of 3 months of balancing (Xin et al. 2013), the final Cd concentrations of low-Cd and high-Cd soils were 2.9 and $4.7 \mathrm{mg} / \mathrm{kg}$, respectively.

\section{Plant materials and experimental design}

In total, 30 eggplant cultivars were used in this study (Table 1). Seeds of each cultivar were mainly acquired from an online trading platform and local markets in Hengyang, China. The collected seeds were sown in the sand and transferred into plastic pots on the 7th day after germination. Each plastic pot, with a diameter of $22 \mathrm{~cm}$ (top) and $18 \mathrm{~cm}$ (bottom) and a height of $15 \mathrm{~cm}$, was filled with $5.0 \mathrm{~kg}$ of the prepared soil. The experiment was laid out in a completely randomized design with three replicates. For each pot, $3.0 \mathrm{~g}$ of solid compound fertilizer (N:P:K = 15:15:15) was applied every 2 weeks thereafter. 


\section{Soil and plant samplings and chemical analyses}

After 3 months of growth, the eggplant samples were harvested. The fruits, leaves, stems, and roots were separately washed thoroughly with tap water, and the roots were soaked for $15 \mathrm{~min}$ in ice-cold $5 \mathrm{mM} \mathrm{CaCl}_{2}$ solution to remove the Cd adsorbed on its surface. All harvested samples were thoroughly washed with deionized water three times, and their fresh weights were recorded after water on the surface was completely evaporated. The harvested fresh samples were divided into two parts for $\mathrm{Cd}$ concentration measurements and $\mathrm{Cd}$ subcellular distribution.

\section{Subcellular distribution of cadmium}

The subcellular distribution of Cd was measured using the method described by Guo et al. (2018). The root, stem, and leaf tissues of each frozen sample were homogenized on ice in the presence of extraction buffer ( $50 \mathrm{mM}$ Tris- $\mathrm{HCl}, 250 \mathrm{mM}$ sucrose, $1.0 \mathrm{mM} \mathrm{C}_{4} \mathrm{H}_{10} \mathrm{O}_{2} \mathrm{~S}_{2}$, and $5.0 \mathrm{mM}$ ascorbic acid).

The cell walls and cell wall debris (F1) were obtained by sieving the homogenate with a nylon cloth $(80 \mu \mathrm{m})$. The filtrate was centrifuged at $2,000 \times \mathrm{g}$ for 15 min (Beckman JA-25.50 rotor, Fullerton, CA, USA) to collect the pellet (F2) containing chloroplasts or trophoplasts. Thereafter, the membrane and organelle (F3) and vacuole and its contents (F4) were separated by centrifuging the supernatant at $15,000 \times \mathrm{g}$ for 40 min. All the steps were performed at $4{ }^{\circ} \mathrm{C}$.

\section{Detection of cadmium concentrations}

The oven-dried plant samples and the subcellular fractions were digested with $\mathrm{HNO}_{3}-\mathrm{H}_{2} \mathrm{O}_{2}(10: 3, \mathrm{v} / \mathrm{v}$ ) in a microwave oven (Microwave digester XT-9900A, Shanghai Xintuo Analytical Instruments Co., Ltd., China). The Cd concentrations of the digested samples were measured using a flame atomic absorption spectrophotometer (Hitachi Z-2300, Japan). To ensure data accuracy and quality control of the test, plant GBW07605 (provided by the National Research Center for CRM, China) was used as a certified reference material (CRM).

\section{Safety standard and statistical methods}

According to the General Standard for Contaminants and Toxins in Food and Feed (CODEX STAN 193-1995, Revision 4, 2009)(FAO 2019), the maximum Cd limitation $(0.05 \mathrm{mg} / \mathrm{kg})$ was used to estimate the safety of consuming fruits among the tested eggplant cultivars.

To determine the $\mathrm{Cd}$ tolerance of plants, a commonly used method of biomass response to stress (BRS) was applied. The BRS values were calculated using Eq. 1:

$$
\operatorname{BRS}(\%)=\frac{\left(B_{\text {high }-C d}\right)-\left(B_{\text {low }-C d}\right)}{\left(B_{\text {low }-C d}\right)(100 \%)} \times 100 \%
$$

where $\mathrm{B}_{\text {high-Cd }}$ and $\mathrm{B}_{\text {low-Cd }}$ are the fruit biomass under the low-Cd and high-Cd treatments, respectively.

The Cd uptake abilities of the tested cultivars were evaluated by the net uptake of Cd via roots, which was calculated by dividing the overall Cd content in the whole plant by the fresh weight of the roots (Greger and Löfstedt 2004; Xin et al. 2013) All data were statistically analyzed by applying the least significant difference (LSD) test based on one-way analysis of variance (ANOVA) with Excel 2016 (Microsoft, Washington, USA) and SPSS 22 (SPSS, Inc., Chicago, IL, USA). Correlations were calculated using the Pearson's correlation coefficient.

\section{Results}

\section{Fruit biomass variations under different cadmium exposures}

All eggplants grew normally under CK, low-Cd, and high-Cd treatments, and the average fruit biomass (FW) was 153.36, 115.23, and 91.36 g, respectively, and no dystrophy symptoms of $\mathrm{Cd}$ toxicity were observed, despite the significant biomass difference between treatments $(p<0.01)$. According to the results of fruit BRS (Figure 1), five cultivars had significantly higher fruit biomass under high-Cd treatment, 15 cultivars showed similar fruit biomass between high-Cd and low-Cd treatments, and the other 10 cultivars had lower fruit biomass than the low-Cd treatment. Among these eggplant cultivars, ZHCQ and LDCQ had the highest fruit BRS values, whereas ZCQ, HQYH, and DLQZ had the lowest fruit BRS values, showing that different eggplant cultivars had different tolerance to $\mathrm{Cd}$, and most of them were Cd tolerant cultivars.

\section{Fruit cadmium accumulation in eggplants}

Significant differences $(p<0.05)$ in fruit Cd concentrations were found among the 30 cultivars in each treatment. The average fruit Cd concentrations (fresh weight, FW) of CK, low- and high-Cd treatments were $0.018(0.038-0.004 \mathrm{mg} / \mathrm{kg}), 0.084(0.148-0.005 \mathrm{mg} / \mathrm{kg})$, and $0.194(0.282-0.112 \mathrm{mg} / \mathrm{kg}) \mathrm{mg} / \mathrm{kg}$, respectively (Figure 2). In addition, the maximal differences in fruit Cd concentrations among the cultivars were 3.88-, 3.22-, and 2.52-fold under CK, low- and high-Cd treatments, respectively (Figure 2). Fruit Cd concentrations of all tested cultivars under CK treatment were lower than the Codex $\mathrm{ML}$ for $\mathrm{Cd}(0.05$ $\mathrm{mg} / \mathrm{kg}$ ), while the fruit Cd concentrations of total cultivars exceeded the Codex ML for Cd under high-Cd treatment. However, only MYCQ, ZGQ, and TGZHCQ 
met the standard of Codex ML for Cd under low-Cd treatment, and these three cultivars also accumulated less Cd than the other cultivars under high-Cd treatment (Figure 2B and C). In addition, the fruit Cd concentrations of BXGZ, BGJDQ, and WCCQ were consistently higher than most of the other cultivars under both low-Cd and high-Cd treatments (Figure 2B and C). These results indicate that eggplant cultivars accumulate Cd easily, even when planted in soils with slight Cd contamination.

Correlative analysis showed that some eggplant cultivars had high consistency in fruit Cd accumulation under low-Cd and high-Cd treatments $(p<0.01$, Figure 3), suggesting that the $\mathrm{Cd}$ accumulation abilities of eggplant cultivars are stable and genetically determined. Based on the results of fruit Cd accumulation abilities and correlation analysis, MYCQ and ZGQ were selected as candidates for low-Cd cultivars and BXGZ and WCCQ were selected as candidates for high-Cd cultivars for further investigation.

\section{Leaf, stem, and root cadmium concentrations of the selected cultivars}

Under low-Cd and high-Cd treatments, leaf and stem Cd concentrations of the high-Cd cultivars (BXGZ and WCCQ) were always 2-3 times significantly higher $(p<0.05)$ than those of low-Cd cultivars (MYCQ and ZGQ) (Table 2). However, Cd concentrations in the roots of the low-Cd cultivars were always significantly higher $(p<0.05)$ than those of the high-Cd cultivars. The leaves, stems, and roots of the BXGZ and WCCQ cultivars showed almost the same Cd accumulation ability $(p>0.05)$, regardless of the Cd treatment. In addition, the high-Cd cultivars, MYCQ and ZGQ, also showed no Cd concentration difference $(p<0.05)$ under each Cd treatment, except that the leaf Cd concentration of WCCQ was higher $(p<0.05)$ than that of BXGZ in the high-Cd treatment (Table 2). These results demonstrated that the selected eggplant cultivars had stable characteristics of $\mathrm{Cd}$ accumulation, which should be cultivar-dependent. The different fruit $\mathrm{Cd}$ concentrations of eggplant were not determined by the root Cd concentrations, but by the differences in Cd transport capacity.

\section{Cadmium accumulation of different tissues and the net uptake of roots}

The average total amount of $C d$ accumulated in eggplant was $3.001(2.761-3.301) \mu g, 53.967(49.243-58.079)$ ug, and 94.972 (88.490-100.660) $\mu \mathrm{g}$ under CK, low-Cd, and high-Cd treatments (Figure 4). The average root Cd accumulation of low-Cd cultivars (MYCQ and ZGQ) was 1.18- and 1.15-fold higher than that of high-Cd cultivars (BXGZ and WCCQ) under low- and high-Cd treatments, even though it was slightly lower under CK. The amount of Cd accumulated in the roots of MYCQ were the highest $(p<0.05)$ under CK (1.79 ug), low-Cd treatment (35.71 ug), and under high-Cd treatment (64.33 ug), while the lowest ( $p<$ 0.05) root Cd accumulation was observed in BXGZ, with values of 2.12, 27.36, and 54.13 ug under CK, low- and high- treatments (Figure 4). The average stem, leaf, and fruit $\mathrm{Cd}$ accumulations of low-Cd cultivars were always lower than those of high-Cd cultivars, among which MYCQ and BXGZ were always the lowest $(p<0.05)$ and highest $(p<0.05)$ than the other three selected cultivars, respectively (Figure 4).

Among the selected eggplant cultivars, root Cd net uptake was also significantly different $(p<0.05)($ Table 3$)$. The average root Cd net uptake of the high-Cd cultivars was higher than that of the low-Cd cultivars. Interestingly, MYCQ always possessed the lowest root Cd net uptake compared to the other three selected cultivars $(p<0.05)$, while root Cd net uptake of ZGQ displayed no significant difference $(p>0.05)$ from those of the high-Cd cultivars under low- and high-Cd treatments (Table 3). In addition, no obvious difference in root Cd net uptake was observed $(p>0.05)$ between the high-Cd cultivars (Table 3 ). Based on the results of fruit Cd accumulation and root Cd net uptake, MYCQ and BXGZ were selected for further study.

\section{Subcellular distributions of cadmium in the selected cultivars}

The $\mathrm{Cd}$ concentrations in different subcellular fractions of the fruit, leaf, stem, and root of MYCQ and BXGZ showed the same trend; that is, with the increase in Cd treatment pressure, the $\mathrm{Cd}$ concentrations of each subcellular fraction increased correspondingly (Table 4). As for each subcellular fraction, the mean Cd concentrations of F1 in the fruits, leaves, stems, and roots of both selected cultivars were higher than those of F2, F3, and F4 ( $p<0.05)$. The F1 Cd concentration in the roots of MYCQ was higher than that of BXGZ, and an almost 1.5-fold $(p<0.05)$ difference was observed under all treatments. However, the average Cd concentrations of F1 in the fruit, leaf, and stem of MYCQ were lower than that of BXGZ, especially in the fruit, wherein the Cd concentration difference were 2.1 to 2.6 times. The F2, F3, and F4 in the fruit, leaf, stem, and root of MYCQ and BXGZ were almost the same as F1, with different Cd concentration fold changes from 1.2 to 2.0 times $(p<0.05)$, except for the F2 of fruit and F3 of fruit and leaf under CK $(p>0.05)($ Table 4$)$.

The Cd proportions of F1 in both selected eggplant cultivars were always the highest in all tissues under CK and low-and high-Cd treatments (Figure 5). MYCQ (52-64\%) showed a higher Cd proportion in F1 than in BXGZ (44-62\%) in all tissues, regardless of the Cd treatments. In addition, the Cd proportions of F1 in the fruit and leaf of both selected cultivars were higher than those of stems and roots, which is consistent with the results of Cd concentrations in different subcellular fractions.

F2 Cd proportions were always highly accounted for in all tissues of BXGZ (10-17\%) than that of MYCQ (7-15\%), especially in the stem and root of the highCd treatment. In all tissues, the F2 Cd proportions of MYCQ remained stable except for the decrease in roots under high-Cd treatment. However, the F2 Cd proportions of BXGZ were higher in the stems and roots than in the fruits and leaves under high-Cd treatment (Figure 5).

F3 Cd proportions in BXGZ (9-17\%) were always higher than that of MYCQ (5-10\%) in stems and roots, regardless of whether low- or high-Cd treatment existed. No evident difference in F3 Cd proportions was observed in the fruits and leaves of either cultivar. In addition, the F3 Cd proportions of MYCQ were slightly higher in fruits and leaves than in stems and roots, while the opposite changes were observed in BXGZ (Figure 5).

The Cd proportions of F4 were always the second highest among all the subcellular fractions in both selected cultivars. In roots, the Cd proportions of F4 were higher than those in the stems, leaves, and fruits. The Cd proportions of F4 increased with the increase of Cd treatment in roots, while it showed the opposite

Page $4 / 15$ 
trend in the other tissues. In addition, the Cd proportions of F4 in MYCQ (24-30\%) were obviously higher than that of BXGZ (18-22\%) under low- and high-Cd treatments in roots, and the F4 Cd proportions of fruit, leaf, and stem in MYCQ (18-20\%) were always lower than that of BXGZ (21-22\%) under high-Cd treatments (Figure 5).

\section{Discussion}

\section{Differences in cadmium tolerance and cadmium accumulation existed among eggplant cultivars}

Biomass response to stress is a common method for detecting Cd tolerance in plants (Wang et al. 2009; Guo et al. 2018). In this study, two Cd concentrations were used: low-Cd $(2.9 \mathrm{mg} / \mathrm{kg})$ and high-Cd $(4.7 \mathrm{mg} / \mathrm{kg})$, which covered most of the concentration range of arable land Cd contamination in South China (He et al. 2020; Mamat et al. 2020). Under high-Cd treatment, only 10 out of the 30 eggplant cultivars showed a relatively significant reduction in biomass, while five cultivars even showed a significant increase in biomass, indicating that high levels of Cd tolerance and significant inter-cultivar differences in Cd tolerance exist in eggplants, coinciding with the results of a study on eggplant seedlings by Jiao et al. (2013). As with numerous studies, the Cd accumulation capacity of plants is usually stable and genotype dependent (Grant et al. 2008; Guo et al. 2018; He et al. 2018). Likewise, fruit Cd concentrations of the 30 tested eggplant cultivars showed almost the same order under low- or high-Cd treatment (Figure 4), indicating that eggplant Cd accumulation ability should also be determined by the genotype of cultivars. In the CK and Cd treatments, the differences in Cd concentration among all 30 eggplant varieties were more than 2.52-fold, which could facilitate the screening process of PSC with low Cd accumulation. According to the Codex ML for Cd concentrations in food, MYCQ and ZGQ are considered to be low-Cd cultivars, which are less likely to exert health threats on the human body when cultivated in soils with low Cd concentrations. Comparison of the physiological, biochemical, and molecular variations in response to Cd stress between low-Cd and high-Cd cultivars will help to better understand the mechanism of Cd accumulation in plants (He et al. 2018). Therefore, high-Cd cultivars, BXGZ and WCCQ, were also screened and studied for comparison with the low-Cd cultivars.

In Chinese kale, the shoot biomass of the low-Cd cultivar (DX102) increased with increasing Cd concentration, while the shoot biomass of the high-Cd cultivar (HJK) did not change (Guo et al. 2018). However, Xin et al. (2014) revealed that the fruit biomass of both low- and high-Cd cultivars of hot pepper increased with increasing levels of Cd treatment. In our study, among the selected low-Cd (MYCQ and ZGQ) and high-Cd (BXGZ and WCCQ) Cultivars, ZGQ was the only one with a significant reduction in biomass under high-Cd treatment. These studies indicate that there is no positive correlation between $\mathrm{Cd}$ tolerance and $\mathrm{Cd}$ accumulation in plants. The improvement of plant biomass under $\mathrm{Cd}$ treatment is often explained as hormesis (Carvalho et al. 2020), that is, a certain dose of $\mathrm{Cd}$ stress can promote plant growth. Studies have shown that the proportion of chlorophylls a and b can be modulated in the presence of Cd, which in turn leads to the photosynthetic efficiency of plants (Jia et al. 2013; Muszyńska et al. 2018). However, it is not yet possible to explain the differences in the hormesis effect among different cultivars; detailed mechanisms still need to be investigated.

\section{The cadmium accumulation in the fruits of eggplant is mainly affected by root cadmium uptake capacity and translocation level}

The vast majority of the $\mathrm{Cd}$ that is absorbed and accumulated in plants comes from soil, and plant roots are the organs of plants that are in direct contact with soil; thus, the various Cd uptake capacities of roots could lead to differences in Cd accumulation in plants (Kubo et al. 2011; Li et al. 2019). In the present study, the root Cd net uptake of MYCQ (low-Cd cultivar) was always lower than those of BXGZ (high-Cd cultivar) and WCCQ (high-Cd cultivar), indicating that the lower root Cd uptake contributed to its low Cd accumulation. However, the root Cd net uptake of the other low-Cd cultivar (ZGQ) was not different from those of BXGZ (high-Cd cultivar) and WCCQ (high-Cd cultivar), demonstrating that the mechanism of its low-Cd accumulation in fruits should not be due to the lower Cd uptake but the less Cd transportation to fruits. Studies on hot pepper (Xin et al. 2013), tomato (Borges et al. 2019), and apple (Zhou et al. 2017) showed that root $\mathrm{Cd}$ uptake was not the key factor determining $\mathrm{Cd}$ accumulation in fruits, which is consistent with the Cd accumulation status of low-Cd cultivars in this study.

Cadmium accumulation in the roots of MYCQ and ZGQ was usually higher, while those of the stems, leaves, and fruits in MYCQ and ZGQ were always lower than those in BXGZ and WCCQ (Figure 3), and Cd concentrations in tissues displayed a positive correlation with Cd accumulation (Table 2 and Figure 4), which explained that the dominant factor of fruit $\mathrm{Cd}$ accumulation could be the different $\mathrm{Cd}$ transportation capacities from root to aboveground tissues between low-Cd and high-Cd cultivars. Studies of hot pepper (Xin et al. 2013) and maize (Wang et al. 2016) have revealed that fruit Cd accumulation is only closely related to $\mathrm{Cd}$ redistribution through leaves, but not stems; however, other studies have shown significant correlations among the Cd concentrations in fruit, stem, and root tissues of pepper (Wang et al. 2019) and Chinese wheat (Zhang et al. 2020). In this study, positive correlations were discovered between the $\mathrm{Cd}$ concentrations in fruits, stems, and leaves, and the redistribution capacities of $\mathrm{Cd}$ from stems and leaves to fruits were almost the same among cultivars, which means that the key factor related to fruit $\mathrm{Cd}$ accumulation should be the root Cd transportation capacities from root to aboveground as well. Thus, the difference in fruit $\mathrm{Cd}$ concentrations between low-Cd and high-Cd cultivars should mainly be due to the variation of this capacity in eggplants.

\section{Cell wall and soluble fractions are the most crucial subcellular fractions that determine the level of cadmium accumulation in eggplant.}

Each subcellular component has different functions in the retention, compartment, and detoxification of Cd; thus, the investigation of Cd subcellular distributions is often used to reveal the differences in Cd transport, accumulation, and resistance among species and cultivars (Zhang et al. 2019). The cell 
walls (F1) have been proven to be the first barrier for $\mathrm{Cd}$ entry into plants, the components of which contain many functional groups (-COOH, -OH, -SH, etc.) that can bind large amounts of $\mathrm{Cd}$ and prevent them from entering the cells of plants (Feng et al. 2020). It has been demonstrated that approximately $60-$ $90 \%$ of heavy metals accumulated by plants are adsorbed on the root cell walls (Kang et al. 2015). Wang et al. (2018) showed that differences in the adsorption and compartmentalization capacity of functional groups of the cell wall of soybean roots for Cd resulted in low and high Cd accumulation variations among different cultivars. In this study, the quantities of Cd bound to root cell walls (F1) were 1.5-fold higher in low-Cd cultivars, which should be the main factor leading to the low Cd accumulation. It was also indicated that more functional groups of cellulose, hemicellulose, and pectin should exist in the cell wall of the low-Cd eggplant cultivars. In water spinach, the subcellular distribution of Cd was found to be 1.51-1.79 times higher in the root cell wall of water spinach low-Cd cultivar (QLQ) than in the high-Cd cultivar (T308) (Xin et al 2014), which was consistent with our results. In addition, lower Cd concentrations of F1 were consistently observed in the fruits, leaves, and stems of MYCQ, which also demonstrated that the majority of absorbed Cd was restricted to the roots rather than transported into aboveground tissues. In addition, Cd stress triggered outer cortical cell wall thickening in the roots of QLQ (low-Cd cultivar), and more Cd was restricted to the outer cortex of roots in T308 (high-Cd cultivar), which may be the reason for the low Cd accumulation in its stems and leaves (Xin et al. 2013) Therefore, further mechanistic studies of Cd accumulation differentiation should focus on the components, functional groups, and thickness of cell walls in the low- and high-Cd cultivars of eggplant.

In this study, the Cd concentrations and proportions in chloroplasts and trophoplasts (F2) and membrane organelles (F3) were always higher in all tissues of BXGZ than MYCQ, especially in the stem and root of high-Cd treatment plants, which was in accordance with water spinach (Xin et al. 2013), pakchoi (Xue et al. 2014) and Chinese kale (Guo et al. 2018) under Cd treatments. These results indicate that chloroplast, trophoplast, and membrane organelles might play important roles in Cd detoxification and Cd translocation from the roots to the aboveground tissues of BXGZ. However, further investigation is required to clarify this inference.

It has been well studied that vacuolar sequestration is an essential way for Cd detoxification in plants, especially in the roots (Deng et al. 2019; Li et al. 2020). In the roots of MYCQ, the Cd concentrations and proportions of F4 (vacuolar) were invariably higher than those of BXGZ, which meant that a large amount of $\mathrm{Cd}$ was sequestered in MYCQ, thus leading to the inhibition of $\mathrm{Cd}$ transport to the aboveground tissues, resulting in low $\mathrm{Cd}$ accumulation in aboveground tissues. However, the $\mathrm{Cd}$ concentrations and proportions of F4 in leaves and fruits displayed the opposite trend, indicating that vacuolar sequestration was more responsible for Cd detoxification in leaves and fruits in BXGZ. In water spinach (Huang et al. 2016), pakchoi (Zhou et al. 2016) and peanut (Arachis hypogaea L.) (Yu et al. 2018), the higher expression of adenosine triphosphate-binding cassette transporters in low-Cd cultivars was reported to be responsible for the vacuolar sequestration of $\mathrm{Cd}$-phytochelatin or $\mathrm{Cd}$-glutathione complex, and consequently, reducing root-to-shoot $\mathrm{Cd}$ translocation. Thus, different strategies of $\mathrm{Cd}$ detoxification and translocation depending on vacuole sequestration should be deployed between low-Cd and high-Cd eggplant cultivars.

\section{Declarations}

\section{Acknowledgment}

The reviews and editors are appreciated for comments and suggestions to improve the paper.

\section{Funding}

This research was supported by Natural Science Foundation of Hunan Province, China (Grant No. 2020JJ5119 and N0.2019JJ50113).

\section{Author Contributions}

A total of six authors participated in this work, including Chuang Shen, Hui-ling Fu, Qiong Liao, Bai-fei Huang, Ying-ying Huang* and Jun-liang Xin* .

Conception and design of the study were accomplished by Jun-liang Xin ${ }^{\star}$, Chuang Shen and Ying-ying Huang*; Data collection and analysis was performed by Chuang Shen, Hui-ling Fu and Qiong Liao; first draft was written by Chuang Shen and Bai-fei Huang. Data interpretation and manuscript polishing was carried out by Jun-liang Xin. All the authors approved the final manuscript.

Corresponding author

Correspondence to Ying-ying Huang and Jun-liang Xin.

\section{Ethics declarations}

Competing interests: There is no conflict of interest among the authors.

Ethical approval: Not applicable.

Consent to participate: Not applicable.

Consent to publish: Not applicable. 


\section{Data availability:}

The data of this study are available on request from the corresponding author.

\section{References}

1. Borges, K. L. R., F. Salvato, P. L. Loziuk, D. C. Muddiman, and R. A. Azevedo. 2019. 'Quantitative proteomic analysis of tomato genotypes with differential cadmium tolerance', Environ Sci Pollut Res Int, 26: 26039-51.

2. Carvalho, M. E. A., P. R. C. Castro, and R. A. Azevedo. 2020. 'Hormesis in plants under Cd exposure: From toxic to beneficial element?', J Hazard Mater, 384: 121434.

3. Deng, F., M. Yu, E. Martinoia, and W. Y. Song. 2019. 'Ideal Cereals With Lower Arsenic and Cadmium by Accurately Enhancing Vacuolar Sequestration Capacity', Front Genet, 10: 322.

4. FAO. 2019. 'General Standard for Contaminants and Toxins in Food and Feed', FAO. http://www.fao.org/fao-who-codexalimentarius/sh-proxy/en/? Ink=1\&url=https\%253A\%252F\%252Fworkspace.fao.org\%252Fsites\%252Fcodex\%252FStandards\%252FCXS\%2B193-1995\%252FCXS_193e.pdf.

5. FAOSTAT. 2020. 'FAO Statistical Database', Accessed December 22. http://www.fao.org/faostat/en/\#data/QC.

6. Feng, R., L. Lei, J. Su, R. Zhang, Y. Zhu, W. Chen, L. Wang, R. Wang, J. Dai, Z. Lin, Y. Li, B. Liu, Z. Fan, H. Liu, and C. Rensing. 2020. 'Toxicity of different forms of antimony to rice plant: Effects on root exudates, cell wall components, endogenous hormones and antioxidant system', Sci Total Environ, 711: 134589.

7. Grant, C. A., J. M. Clarke, S. Duguid, and R. L. Chaney. 2008. 'Selection and breeding of plant cultivars to minimize cadmium accumulation', Sci Total Environ, 390: 301-10.

8. Greger, Maria, and Martina Löfstedt. 2004. 'Comparison of Uptake and Distribution of Cadmium in Different Cultivars of Bread and Durum Wheat', Crop Science, 44: 501-07.

9. Guo, J. J., X. Tan, H. L. Fu, J. X. Chen, X. X. Lin, Y. Ma, and Z. Y. Yang. 2018. 'Selection for Cd Pollution-Safe Cultivars of Chinese Kale (Brassica alboglabra L. H. Bailey) and Biochemical Mechanisms of the Cultivar-Dependent Cd Accumulation Involving in Cd Subcellular Distribution', J Agric Food Chem, 66: 1923-34.

10. He, C. T., Y. H. Zhou, Y. Y. Huang, H. L. Fu, X. S. Wang, F. Y. Gong, X. Tan, and Z. Y. Yang. 2018. 'Different Proteomic Processes Related to the CultivarDependent Cadmium Accumulation of Amaranthus gangeticus', J Agric Food Chem, 66: 1085-95.

11. He, L., W. Hu, X. Wang, Y. Liu, Y. Jiang, Y. Meng, Q. Xiao, X. Guo, Y. Zhou, Y. Bi, and Y. Lu. 2020. 'Analysis of Heavy Metal Contamination of Agricultural Soils and Related Effect on Population Health-A Case Study for East River Basin in China', Int J Environ Res Public Health, 17.

12. Huang, Y. Y., Y. X. Mu, C. T. He, H. L. Fu, X. S. Wang, F. Y. Gong, and Z. Y. Yang. 2018. 'Cadmium and lead accumulations and agronomic quality of a newly bred pollution-safe cultivar (PSC) of water spinach', Environ Sci Pollut Res Int, 25: 11152-62.

13. Huang, Y. Y., C. Shen, J. X. Chen, C. T. He, Q. Zhou, X. Tan, J. G. Yuan, and Z. Y. Yang. 2016. 'Comparative Transcriptome Analysis of Two Ipomoea aquatica Forsk. Cultivars Targeted To Explore Possible Mechanism of Genotype-Dependent Accumulation of Cadmium', J Agric Food Chem, 64: 5241-50.

14. Jia, L., X. He, W. Chen, Z. Liu, Y. Huang, and S. Yu. 2013. 'Hormesis phenomena under Cd stress in a hyperaccumulator-Lonicera japonica Thunb', Ecotoxicology, 22: 476-85.

15. Jiao, H. J. Niu, M. F. Wei, S. H. Li, Y. M. Wang, S. S. 2013. 'Differences of Accumulating and Enduring Cadmium among Eggplant Seedlings', Asian Journal of Ecotoxicology, 8: 413-18.

16. Kang, W., J. Bao, J. Zheng, H. Hu, and J. Du. 2015. 'Distribution and chemical forms of copper in the root cells of castor seedlings and their tolerance to copper phytotoxicity in hydroponic culture', Environ Sci Pollut Res Int, 22: 7726-34.

17. Kubo, Katashi, Yoshiaki Watanabe, Hitoshi Matsunaka, Masako Seki, Masaya Fujita, Naoyuki Kawada, Koichi Hatta, and Takashi Nakajima. 2011. 'Differences in Cadmium Accumulation and Root Morphology in Seedlings of Japanese Wheat Varieties with Distinctive Grain Cadmium Concentration', Plant Production Science, 14: 148-55.

18. Li, H., P. Pu, X. Li, Y. Gong, D. An, L. Zhang, and J. Lv. 2020. 'Sulfur application reduces cadmium uptake in edible parts of pakchoi (Brassica chinensis L.) by cadmium chelation and vacuolar sequestration', Ecotoxicol Environ Saf, 194: 110402.

19. Li, Min, Xiaohuan Xi, Guiyi Xiao, Hangxin Cheng, Zhongfang Yang, Guohua Zhou, Jiayu Ye, and Zhonghui Li. 2014. 'National multi-purpose regional geochemical survey in China', Journal of Geochemical Exploration, 139: 21-30.

20. Li, X. F.; Chen, Z. B.; Chen, Z. Q.; Zhang, Y. H.; Wang, Q. Y.; Huang, M. L. 2013. 'Concentrations and Health Risk Asesment of Heavy Metals in Soil and Vegetables from REEs Mining Area『Fujian Province', journal of Soil and Water Conservation (Chinese), 27: 146-51.

21. Li, Z. R., J. X. Wang, L. Z. An, J. B. Tan, F. D. Zhan, J. Wu, and Y. Q. Zu. 2019. 'Effect of root exudates of intercropping Vicia faba and Arabis alpina on accumulation and sub-cellular distribution of lead and cadmium', Int J Phytoremediation, 21: 4-13.

22. Mamat, A., Z. Zhang, Z. Mamat, F. Zhang, and C. Yinguang. 2020. 'Pollution assessment and health risk evaluation of eight (metalloid) heavy metals in farmland soil of 146 cities in China', Environ Geochem Health, 42: 3949-63.

23. Muszyńska, E., E. Hanus-Fajerska, and K. Ciarkowska. 2018. 'Studies on lead and cadmium toxicity in Dianthus carthusianorum calamine ecotype cultivated in vitro', Plant Biol (Stuttg), 20: 474-82.

24. Qiu, Q., Y. Wang, Z. Yang, and J. Yuan. 2011. 'Effects of phosphorus supplied in soil on subcellular distribution and chemical forms of cadmium in two Chinese flowering cabbage (Brassica parachinensis L.) cultivars differing in cadmium accumulation', Food Chem Toxicol, 49: 2260-7. 
25. Saini, Dinesh Kumar, and Prashant Kaushik. 2019. 'Visiting eggplant from a biotechnological perspective: A review', Scientia Horticulturae, $253: 327-40$.

26. Shen, C., Y. Y. Huang, C. T. He, Q. Zhou, J. X. Chen, X. Tan, S. Mubeen, J. G. Yuan, and Z. Y. Yang. 2017. 'Comparative analysis of cadmium responsive microRNAs in roots of two Ipomoea aquatica Forsk. cultivars with different cadmium accumulation capacities', Plant Physiol Biochem, 111: 329-39.

27. Wang, A., M. Wang, Q. Liao, and X. He. 2016. 'Characterization of Cd translocation and accumulation in 19 maize cultivars grown on Cd-contaminated soil: implication of maize cultivar selection for minimal risk to human health and for phytoremediation', Environ Sci Pollut Res Int, 23: 5410-9.

28. Wang, J., J. Yuan, Z. Yang, B. Huang, Y. Zhou, J. Xin, Y. Gong, and H. Yu. 2009. 'Variation in cadmium accumulation among 30 cultivars and cadmium subcellular distribution in 2 selected cultivars of water spinach (Ipomoea aquatica Forsk.)', J Agric Food Chem, 57: 8942-9.

29. Wang, P., B. Yang, H. Wan, X. Fang, and C. Yang. 2018. 'The differences of cell wall in roots between two contrasting soybean cultivars exposed to cadmium at young seedlings', Environ Sci Pollut Res Int, 25: 29705-14.

30. Wang, Y., Y. Su, and S. Lu. 2019. 'Cd accumulation and transfer in pepper (Capsicum annuum L.) grown in typical soils of China: pot experiments', Environ Sci Pollut Res Int, 26: 36558-67.

31. Xin, J., and B. Huang. 2014. 'Subcellular distribution and chemical forms of cadmium in two hot pepper cultivars differing in cadmium accumulation', $J$ Agric Food Chem, 62: 508-15.

32. Xin, Junliang, Baifei Huang, Aiqun Liu, Wenjing Zhou, and Kebing Liao. 2013. 'Identification of hot pepper cultivars containing low Cd levels after growing on contaminated soil: uptake and redistribution to the edible plant parts', Plant and Soil, 373: 415-25.

33. Xin, Junliang, Baifei Huang, Zhongyi Yang, Jiangang Yuan, and Yadong Zhang. 2013. 'Comparison of cadmium subcellular distribution in different organs of two water spinach (Ipomoea aquatica Forsk.) cultivars', Plant and Soil, 372: 431-44.

34. Xue, Meng, Yihui Zhou, Zhongyi Yang, Biyun Lin, Jiangang Yuan, and Shanshan Wu. 2014. 'Comparisons in subcellular and biochemical behaviors of cadmium between low-Cd and high-Cd accumulation cultivars of pakchoi (Brassica chinensis L.)', Frontiers of Environmental Science \& Engineering, 8: 226-38.

35. Yu, R., Y. Ma, Y. Li, X. Li, C. Liu, X. Du, and G. Shi. 2018. 'Comparative transcriptome analysis revealed key factors for differential cadmium transport and retention in roots of two contrasting peanut cultivars', BMC Genomics, 19: 938.

36. Yuan, H., L. Sun, P. Tai, W. Liu, X. Li, and L. Hao. 2019. 'Effects of grafting on root-to-shoot cadmium translocation in plants of eggplant (Solanum melongena) and tomato (Solanum lycopersicum)', Sci Total Environ, 652: 989-95.

37. Zhang, K., J. Yuan, W. Kong, and Z. Yang. 2013. 'Genotype variations in cadmium and lead accumulations of leafy lettuce (Lactuca sativa L.) and screening for pollution-safe cultivars for food safety', Environ Sci Process Impacts, 15: 1245-55.

38. Zhang, L., C. Zhang, B. Du, B. Lu, D. Zhou, J. Zhou, and J. Zhou. 2020. 'Effects of node restriction on cadmium accumulation in eight Chinese wheat (Triticum turgidum) cultivars', Sci Total Environ, 725: 138358.

39. Zhang, Z. H., T. Zhou, T. J. Tang, H. X. Song, C. Y. Guan, J. Y. Huang, and Y. P. Hua. 2019. 'A multiomics approach reveals the pivotal role of subcellular reallocation in determining rapeseed resistance to cadmium toxicity', J Exp Bot, 70: 5437-55.

40. Zhou, J., H. Wan, J. He, D. Lyu, and H. Li. 2017. 'Integration of Cadmium Accumulation, Subcellular Distribution, and Physiological Responses to Understand Cadmium Tolerance in Apple Rootstocks', Front Plant Sci, 8: 966.

41. Zhou, Q., J. J. Guo, C. T. He, C. Shen, Y. Y. Huang, J. X. Chen, J. H. Guo, J. G. Yuan, and Z. Y. Yang. 2016. 'Comparative Transcriptome Analysis between Low- and High-Cadmium-Accumulating Genotypes of Pakchoi (Brassica chinensis L.) in Response to Cadmium Stress', Environ Sci Technol, 50: 6485-94.

\section{Tables}

Table 1

Tested eggplant (Solanum melongena L.) cultivars and the seeds providers 


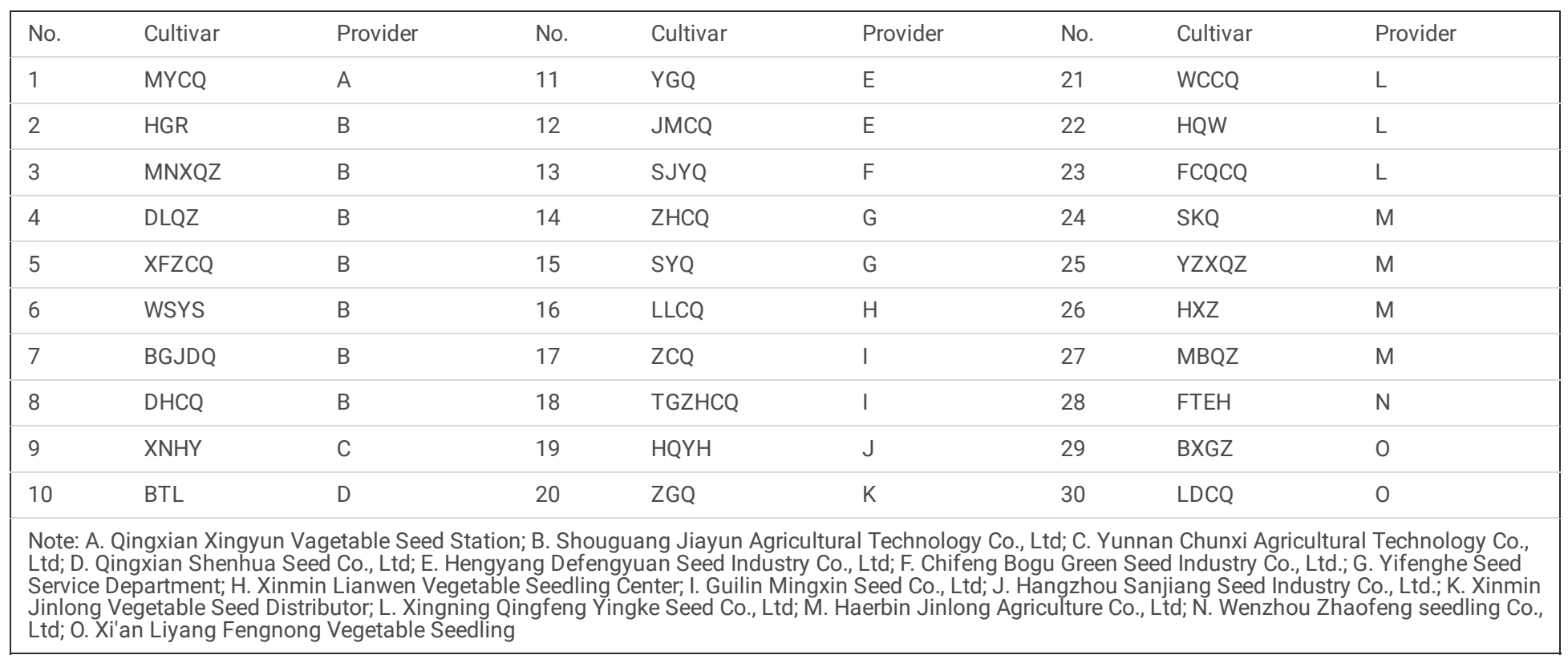

Table 2

Cd concentrations $(\mathrm{mg} / \mathrm{kg}, \mathrm{fw})$ of selected eggplant (Solanum melongena L.) cultivars under different treatments

\begin{tabular}{|c|c|c|c|c|}
\hline & & $\mathrm{Ck}$ & Low-Cd & High-Cd \\
\hline \multirow[t]{4}{*}{ Root } & MYCQ & $0.36 \pm 0.06 \mathrm{a}$ & $3.77 \pm 0.64$ a & $7.42 \pm 0.32$ a \\
\hline & ZGQ & $0.32 \pm 0.04 a$ & $3.64 \pm 0.23 \mathrm{a}$ & $7.79 \pm 0.41 \mathrm{a}$ \\
\hline & BXGZ & $0.27 \pm 0.06 b$ & $2.81 \pm 0.36 b$ & $5.62 \pm 0.23 b$ \\
\hline & WCCQ & $0.26 \pm 0.05 b$ & $2.51 \pm 0.43 b$ & $5.58 \pm 0.27 b$ \\
\hline \multirow[t]{4}{*}{ Stem } & MYCQ & $0.05 \pm 0.01 b$ & $0.54 \pm 0.05 b$ & $1.39 \pm 0.11 b$ \\
\hline & ZGQ & $0.05 \pm 0.01 \mathrm{~b}$ & $0.61 \pm 0.06 b$ & $1.43 \pm 0.13 b$ \\
\hline & BXGZ & $0.07 \pm 0.01 \mathrm{a}$ & $0.73 \pm 0.03 a$ & $1.81 \pm 0.10 a$ \\
\hline & WCCQ & $0.07 \pm 0.01 \mathrm{a}$ & $0.80 \pm 0.05 a$ & $1.72 \pm 0.09 a$ \\
\hline \multirow[t]{4}{*}{ Leaf } & MYCQ & $0.03 \pm 0.00 \mathrm{~b}$ & $0.40 \pm 0.05 b$ & $1.22 \pm 0.12 b$ \\
\hline & ZGQ & $0.03 \pm 0.00 \mathrm{~b}$ & $0.45 \pm 0.04 b$ & $1.36 \pm 0.05 b$ \\
\hline & BXGZ & $0.04 \pm 0.00 \mathrm{a}$ & $0.74 \pm 0.06$ a & $1.56 \pm 0.13 a$ \\
\hline & WCCQ & $0.04 \pm 0.00 \mathrm{a}$ & $0.68 \pm 0.06 a$ & $1.53 \pm 0.06 \mathrm{a}$ \\
\hline
\end{tabular}

Table 3

Cd net uptake via roots $(\mathrm{mg} / \mathrm{kg}, \mathrm{fw})$ in eggplant cultivars under different treatments.

\begin{tabular}{|llll|}
\hline cultivars & control & Low-Cd & High-Cd \\
\hline MYCQ & $8.69 \pm 0.65 \mathrm{~b}$ & $45.18 \pm 3.36 \mathrm{~b}$ & $88.20 \pm 4.42 \mathrm{~b}$ \\
\hline ZGQ & $6.94 \pm 0.63 \mathrm{~b}$ & $54.76 \pm 4.45 \mathrm{a}$ & $94.29 \pm 3.89 \mathrm{ab}$ \\
\hline BXGZ & $7.09 \pm 0.58 \mathrm{a}$ & $58.91 \pm 5.05 \mathrm{a}$ & $100.32 \pm 7.31 \mathrm{a}$ \\
\hline WCCQ & $8.36 \pm 0.64 \mathrm{a}$ & $52.49 \pm 3.77 \mathrm{ab}$ & $96.04 \pm 5.49 \mathrm{ab}$ \\
\hline Note: Values represent the mean \pm SD $(\mathrm{n}=3)$. Values followed by different lowercase letters in the same column are significantly different at $\mathrm{p}<0.05$. \\
\hline
\end{tabular}


Table 4

Cd Subcellular Distribution in tissues of Low-Cd (MYCQ) and High-Cd (BXGZ) eggplant Cultivars under different treatments.

\begin{tabular}{|c|c|c|c|c|c|c|c|c|c|}
\hline \multirow{2}{*}{$\begin{array}{l}\text { Subcellular } \\
\text { fraction }\end{array}$} & \multirow[t]{2}{*}{ treatment } & \multicolumn{2}{|l|}{ fruit } & \multicolumn{2}{|l|}{ leaf } & \multicolumn{2}{|l|}{ stem } & \multicolumn{2}{|l|}{ root } \\
\hline & & MYCQ & $B X G Z$ & MYCQ & $\mathrm{BXGZ}$ & MYCQ & BXGZ & MYCQ & $B X G Z$ \\
\hline \multirow[t]{3}{*}{$\mathrm{F} 1$} & CK & $\begin{array}{l}0.036 \pm 0.003 \\
\mathrm{~b}\end{array}$ & $\begin{array}{l}0.047 \pm 0.002 \\
\mathrm{a}\end{array}$ & $\begin{array}{l}0.035 \pm 0.003 \\
\mathrm{a}\end{array}$ & $\begin{array}{l}0.048 \pm 0.002 \\
\mathrm{a}\end{array}$ & $\begin{array}{l}0.061 \pm 0.009 \\
\mathrm{a}\end{array}$ & $\begin{array}{l}0.043 \pm 0.006 \\
\mathrm{a}\end{array}$ & $\begin{array}{l}0.080 \pm 0.002 \\
\mathrm{~b}\end{array}$ & $\begin{array}{l}0.088 \pm 0.002 \\
a\end{array}$ \\
\hline & Low-Cd & $\begin{array}{l}0.043 \pm 0.002 \\
b\end{array}$ & $\begin{array}{l}0.083 \pm 0.002 \\
a\end{array}$ & $\begin{array}{l}0.052 \pm 0.002 \\
b\end{array}$ & $\begin{array}{l}0.085 \pm 0.002 \\
a\end{array}$ & $\begin{array}{l}0.631 \pm 0.030 \\
\mathrm{~b}\end{array}$ & $\begin{array}{l}0.898 \pm 0.062 \\
a\end{array}$ & $\begin{array}{l}2.313 \pm 0.188 \\
b\end{array}$ & $\begin{array}{l}1.586 \pm 0.179 \\
\mathrm{a}\end{array}$ \\
\hline & High-Cd & $\begin{array}{l}0.073 \pm 0.001 \\
b\end{array}$ & $\begin{array}{l}0.142 \pm 0.008 \\
a\end{array}$ & $\begin{array}{l}1.229 \pm 0.102 \\
b\end{array}$ & $\begin{array}{l}1.876 \pm 0.041 \\
a\end{array}$ & $\begin{array}{l}2.427 \pm 0.251 \\
b\end{array}$ & $\begin{array}{l}3.473 \pm 0.093 \\
a\end{array}$ & $\begin{array}{l}6.713 \pm 0.289 \\
b\end{array}$ & $\begin{array}{l}5.420 \pm 0.242 \\
a\end{array}$ \\
\hline \multirow[t]{3}{*}{ F2 } & CK & $\begin{array}{l}0.014 \pm 0.001 \\
a\end{array}$ & $\begin{array}{l}0.013 \pm 0.001 \\
\mathrm{a}\end{array}$ & $\begin{array}{l}0.003 \pm 0.001 \\
\mathrm{a}\end{array}$ & $\begin{array}{l}0.003 \pm 0.001 \\
a\end{array}$ & $\begin{array}{l}0.024 \pm 0.006 \\
a\end{array}$ & $\begin{array}{l}0.023 \pm 0.007 \\
a\end{array}$ & $\begin{array}{l}0.023 \pm 0.006 \\
a\end{array}$ & $\begin{array}{l}0.020 \pm 0.003 \\
\mathrm{a}\end{array}$ \\
\hline & Low-Cd & $\begin{array}{l}0.031 \pm 0.001 \\
\text { b }\end{array}$ & $\begin{array}{l}0.051 \pm 0.001 \\
\mathrm{a}\end{array}$ & $\begin{array}{l}0.039 \pm 0.002 \\
b\end{array}$ & $\begin{array}{l}0.151 \pm 0.002 \\
\mathrm{a}\end{array}$ & $\begin{array}{l}0.228 \pm 0.033 \\
\mathrm{~b}\end{array}$ & $\begin{array}{l}0.583 \pm 0.110 \\
\mathrm{a}\end{array}$ & $\begin{array}{l}1.279 \pm 0.095 \\
\text { b }\end{array}$ & $\begin{array}{l}1.662 \pm 0.084 \\
a\end{array}$ \\
\hline & High-Cd & $\begin{array}{l}0.051 \pm 0.001 \\
b\end{array}$ & $\begin{array}{l}0.072 \pm 0.002 \\
a\end{array}$ & $\begin{array}{l}0.145 \pm 0.011 \\
\mathrm{~b}\end{array}$ & $\begin{array}{l}0.303 \pm 0.029 \\
a\end{array}$ & $\begin{array}{l}0.610 \pm 0.087 \\
\text { b }\end{array}$ & $\begin{array}{l}1.049 \pm 0.119 \\
\mathrm{a}\end{array}$ & $\begin{array}{l}2.257 \pm 0.112 \\
b\end{array}$ & $\begin{array}{l}3.334 \pm 0.175 \\
\text { a }\end{array}$ \\
\hline \multirow[t]{3}{*}{ F3 } & CK & $\begin{array}{l}0.013 \pm 0.001 \\
b\end{array}$ & $\begin{array}{l}0.022 \pm 0.001 \\
a\end{array}$ & $\begin{array}{l}0.033 \pm 0.002 \\
\mathrm{~b}\end{array}$ & $0.033 \pm 0.002 a$ & $\begin{array}{l}0.027 \pm 0.004 \\
\mathrm{~b}\end{array}$ & $\begin{array}{l}0.033 \pm 0.004 \\
a\end{array}$ & $\begin{array}{l}0.023 \pm 0.001 \\
a\end{array}$ & $\begin{array}{l}0.025 \pm 0.002 \\
\mathrm{a}\end{array}$ \\
\hline & Low-Cd & $\begin{array}{l}0.031 \pm 0.001 \\
b\end{array}$ & $\begin{array}{l}0.042 \pm 0.001 \\
a\end{array}$ & $\begin{array}{l}0.082 \pm 0.003 \\
\mathrm{~b}\end{array}$ & $\begin{array}{l}0.124 \pm 0.002 \\
a\end{array}$ & $\begin{array}{l}0.195 \pm 0.020 \\
\mathrm{~b}\end{array}$ & $\begin{array}{l}0.520 \pm 0.041 \\
a\end{array}$ & $\begin{array}{l}0.548 \pm 0.046 \\
b\end{array}$ & $\begin{array}{l}0.927 \pm 0.104 \\
\mathrm{a}\end{array}$ \\
\hline & High-Cd & $\begin{array}{l}0.042 \pm 0.002 \\
\mathrm{~b}\end{array}$ & $\begin{array}{l}0.082 \pm 0.002 \\
\mathrm{a}\end{array}$ & $\begin{array}{l}0.148 \pm 0.006 \\
\mathrm{~b}\end{array}$ & $\begin{array}{l}0.241 \pm 0.002 \\
\mathrm{a}\end{array}$ & $\begin{array}{l}0.343 \pm 0.066 \\
\mathrm{~b}\end{array}$ & $\begin{array}{l}0.736 \pm 0.061 \\
\mathrm{a}\end{array}$ & $\begin{array}{l}1.236 \pm 0.124 \\
\text { b }\end{array}$ & $\begin{array}{l}2.700 \pm 0.442 \\
a\end{array}$ \\
\hline \multirow[t]{3}{*}{$\mathrm{F} 4$} & CK & $\begin{array}{l}0.015 \pm 0.001 \\
a\end{array}$ & $\begin{array}{l}0.014 \pm 0.001 \\
a\end{array}$ & $\begin{array}{l}0.046 \pm 0.001 \\
a\end{array}$ & $\begin{array}{l}0.044 \pm 0.003 \\
a\end{array}$ & $\begin{array}{l}0.034 \pm 0.006 \\
a\end{array}$ & $\begin{array}{l}0.021 \pm 0.003 \\
a\end{array}$ & $\begin{array}{l}0.051 \pm 0.003 \\
a\end{array}$ & $\begin{array}{l}0.040 \pm 0.002 \\
b\end{array}$ \\
\hline & Low-Cd & $\begin{array}{l}0.021 \pm 0.001 \\
a\end{array}$ & $\begin{array}{l}0.021 \pm 0.001 \\
a\end{array}$ & $\begin{array}{l}0.119 \pm 0.011 \\
b\end{array}$ & $\begin{array}{l}0.175 \pm 0.013 \\
a\end{array}$ & $\begin{array}{l}0.362 \pm 0.072 \\
\mathrm{~b}\end{array}$ & $\begin{array}{l}0.663 \pm 0.060 \\
a\end{array}$ & $\begin{array}{l}0.646 \pm 0.020 \\
b\end{array}$ & $\begin{array}{l}0.582 \pm 0.009 \\
\mathrm{a}\end{array}$ \\
\hline & High-Cd & $\begin{array}{l}0.034 \pm 0.001 \\
a\end{array}$ & $\begin{array}{l}0.036 \pm 0.001 \\
a\end{array}$ & $\begin{array}{l}0.498 \pm 0.028 \\
b\end{array}$ & $\begin{array}{l}0.635 \pm 0.026 \\
a\end{array}$ & $\begin{array}{l}0.653 \pm 0.058 \\
b\end{array}$ & $\begin{array}{l}0.916 \pm 0.073 \\
a\end{array}$ & $\begin{array}{l}1.558 \pm 0.131 \\
b\end{array}$ & $\begin{array}{l}1.130 \pm 0.077 \\
\mathrm{a}\end{array}$ \\
\hline
\end{tabular}

\section{Figures}




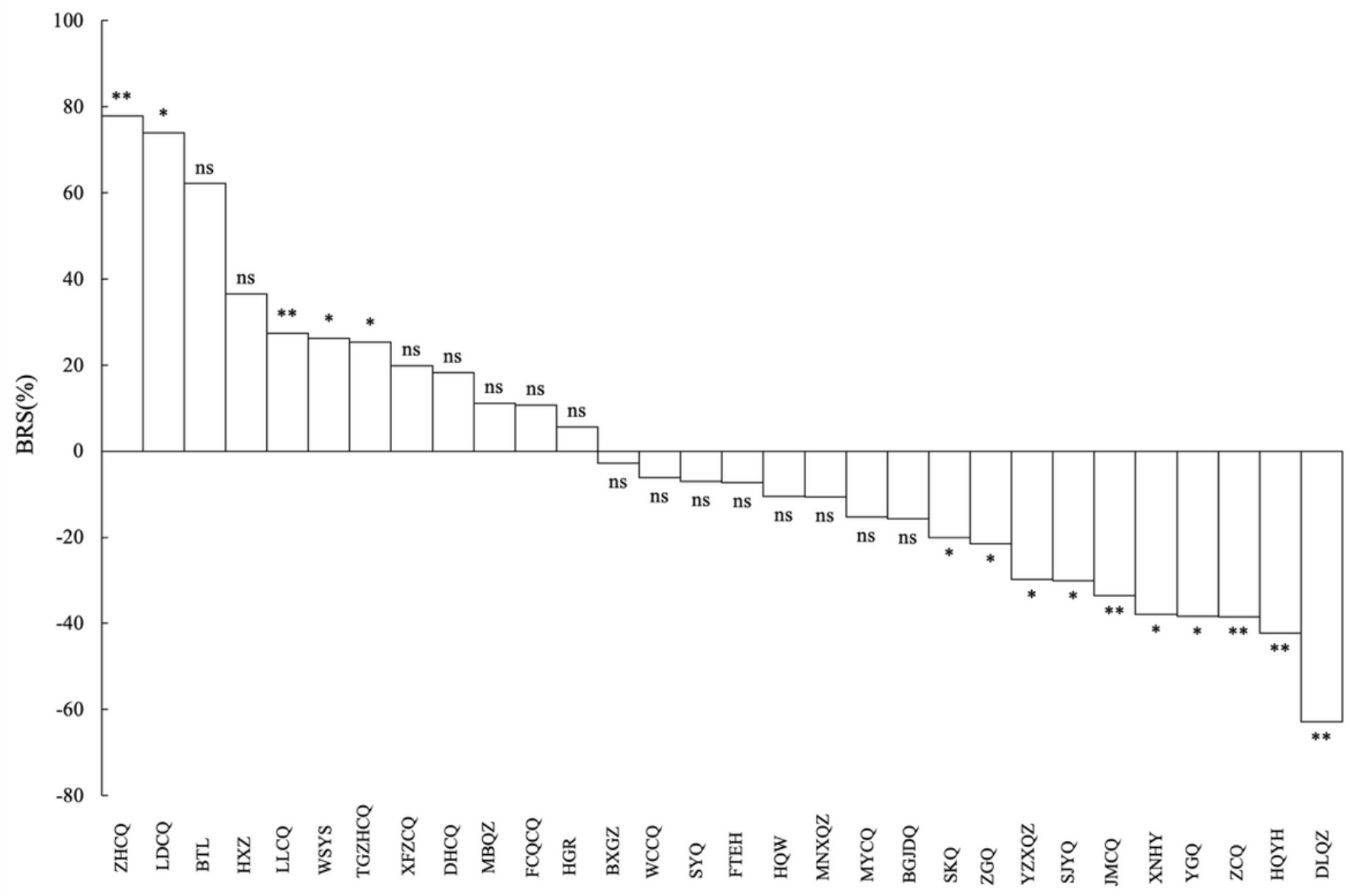

\section{Cultivars}

\section{Figure 1}

The values of fruit biomass responses to stress (BRS) in the selected eggplant cultivars under low-Cd and high-Cd treatments. Note: ns, no significant difference; *, significant difference at $p<0.05$; ${ }^{*}$, significant difference at $p<0.01$. 

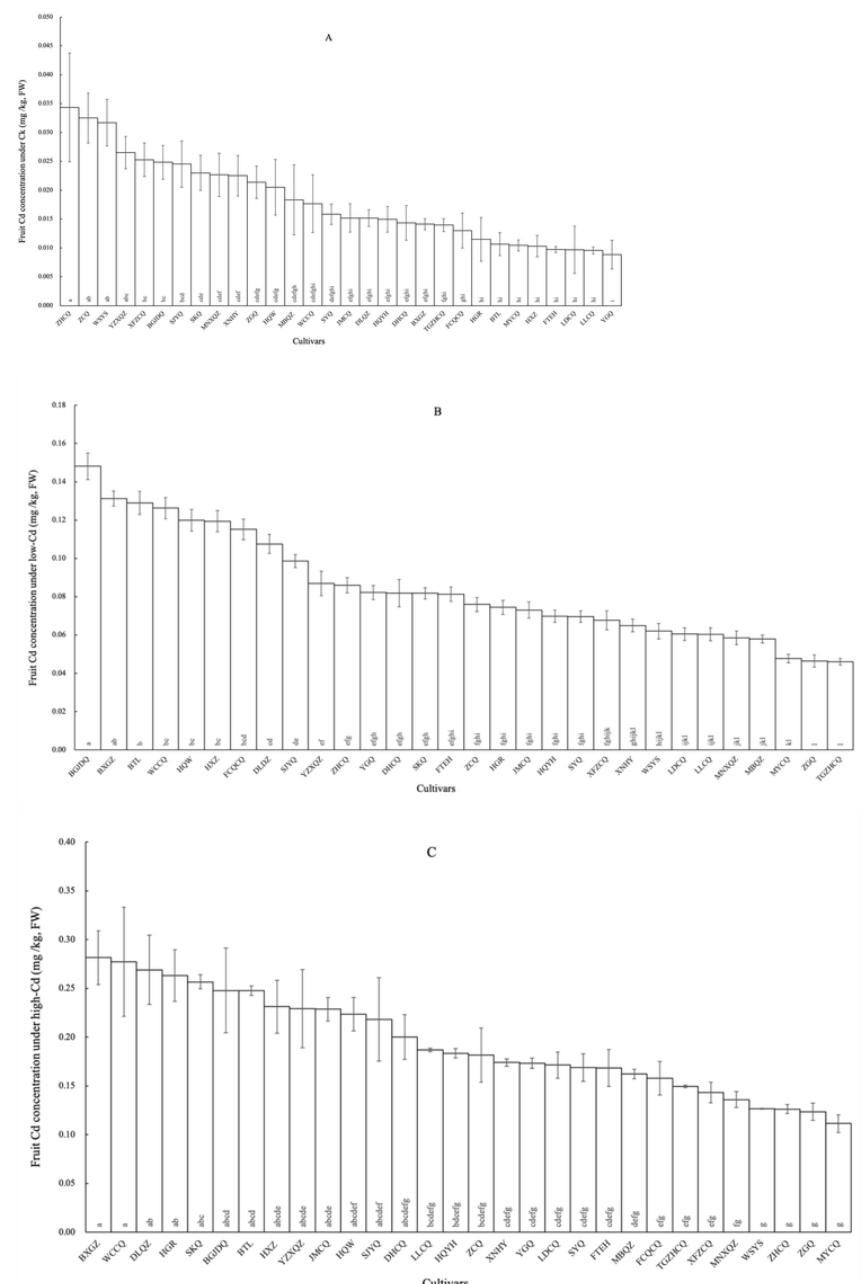

\section{Figure 2}

Fruit Cd concentrations of 30 cultivars under $C K(A)$, low-Cd(B) and high-Cd (C)treatments. Notes: Values are the mean \pm standard error $(n=3)$. Different small letters indicate significant differences $(p<0.05)$ among different cultivars in the same treatment. 


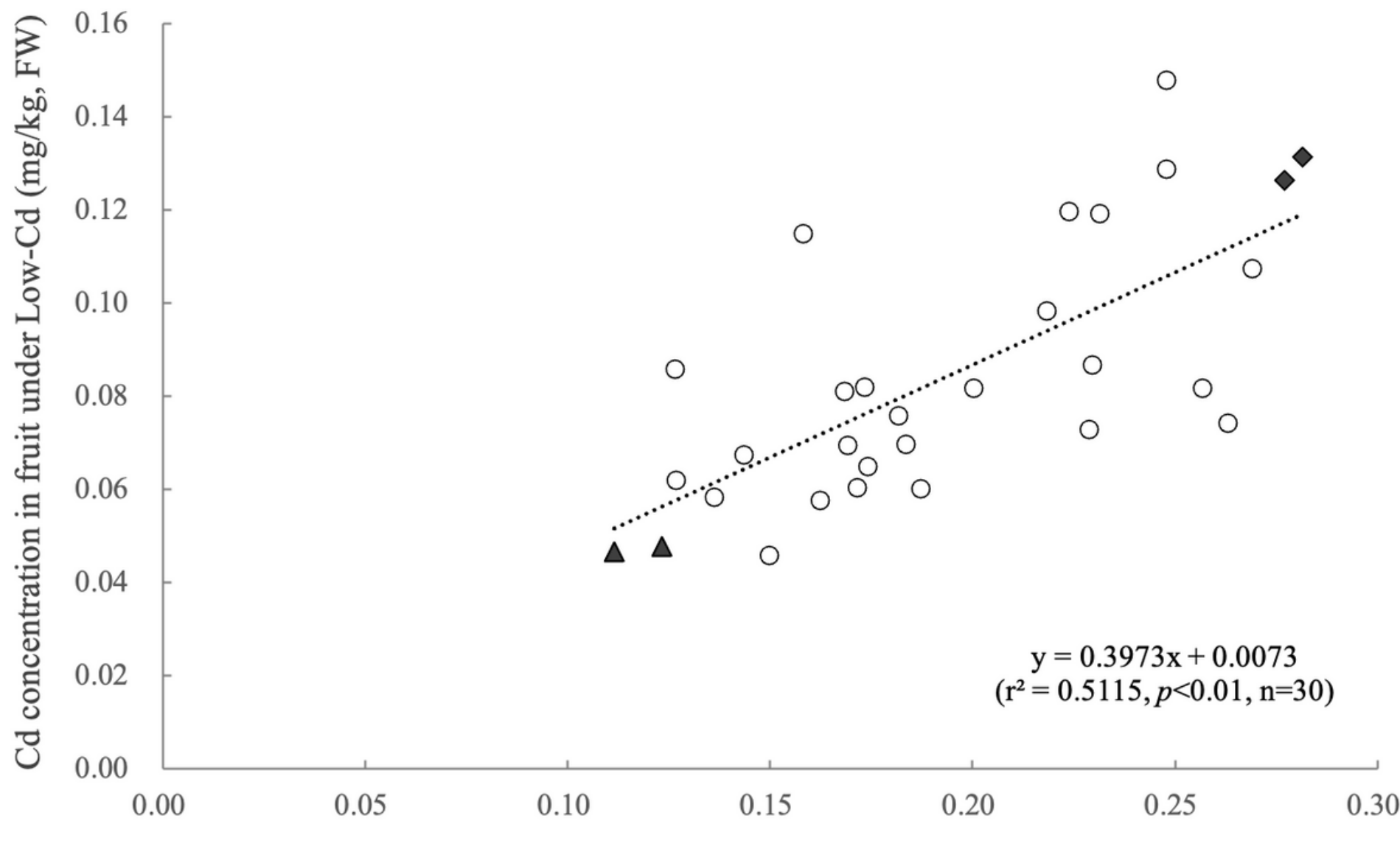

$\mathrm{Cd}$ concentration in fruit under $\mathrm{Hi}-\mathrm{Cd}(\mathrm{mg} / \mathrm{kg}, \mathrm{FW})$

Figure 3

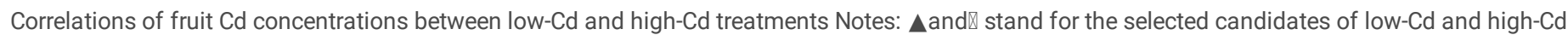
cultivars, respectively. 


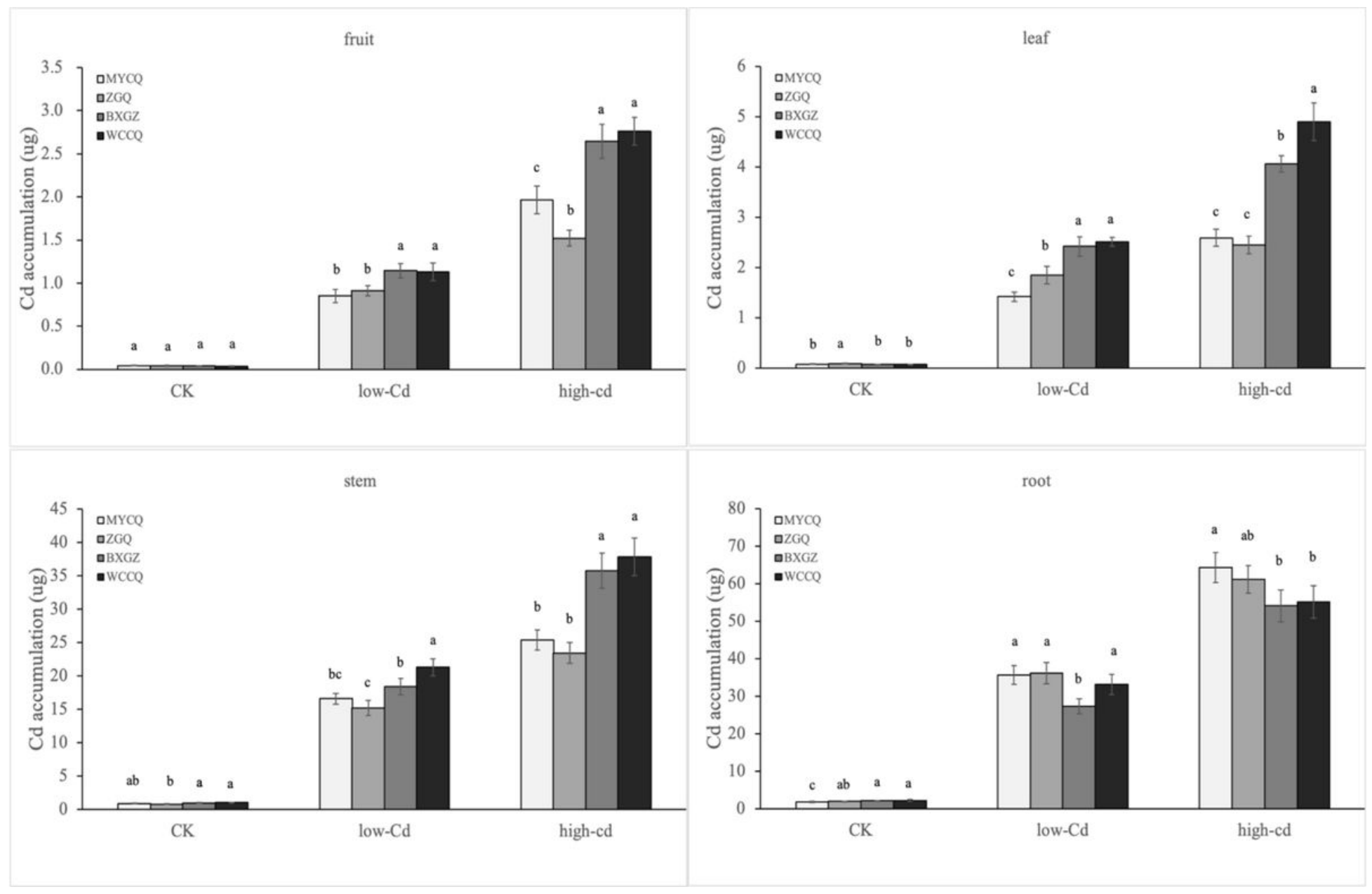

Figure 4

The total amount of $\mathrm{Cd}$ in different tissues of selected eggplant cultivars under different treatments. Notes: Values are the mean \pm standard error ( $\mathrm{n}=3$ ). Different small letters indicate significant differences $(p<0.05)$ among different cultivars in the same treatment. 

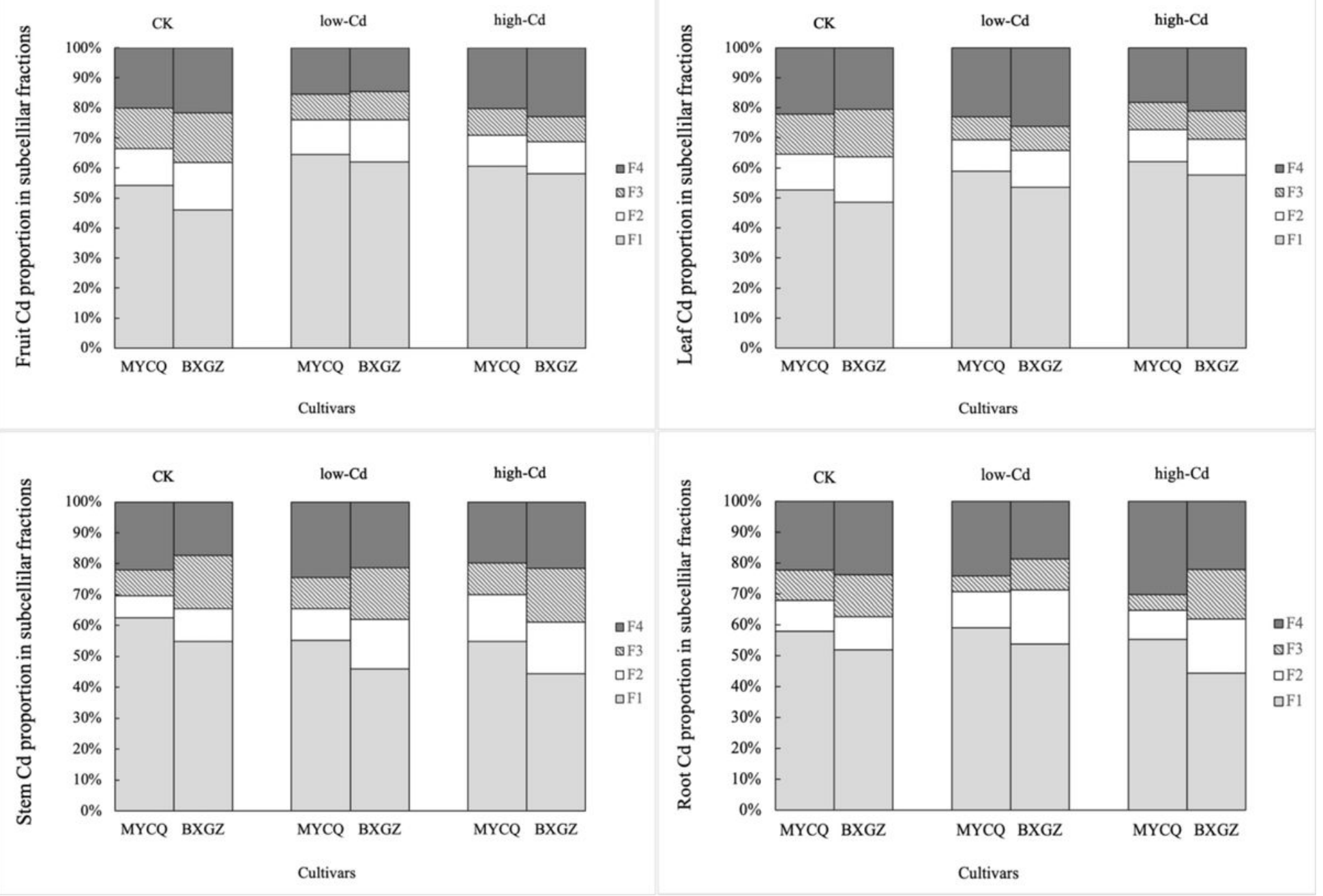

\section{Figure 5}

The proportions of $\mathrm{Cd}$ in subcellular fractions of different tissues of selected eggplant cultivars under different treatments Notes: Cd proportion Irb\%) $=\mathrm{Cd}$ concentration in fraction / (sum of Cd concentrations in all fractions) $\times 100$. 